Table 1. Demographic characteristics

\begin{tabular}{cc}
\hline & $\mathrm{N}=102$ \\
\hline Age, years, mean (SD) & $51.27(14.68)$ \\
Female, $\mathrm{n}(\%)$ & $84(82.4)$ \\
Diagnosis, $\mathrm{n}(\%)$ & $71(69.6)$ \\
-RA & $13(12.7)$ \\
-SLE & $12(11.8)$ \\
-OA & $6(5.8)$ \\
-Other AID & \\
\hline
\end{tabular}

Table 2. Vaccination barriers

$\mathrm{N}=82$

If you didn't receive any of the previous vaccines,

what was the reason? $\mathrm{n}(\%)$

1)Did not was recommended

2) Lack of availability

3) Vaccines don't work

4) Fear of adverse events

5) Previous adverse event

6) Other reason

- Own decision

- Disinformation

22 (26.8)

$21(25.6)$

$13(15.8)$

$8(9.7)$

$3(3.6)$

$8(9.7)$

$7(8.5)$

Results: 102 patients were evaluated: Mean age was 51.27 (SD 14.68) years; $84(82.4 \%)$ were females; $71(69.6 \%)$ had rheumatoid arthritis, $13(12.7 \%)$ had systemic lupus erythematosus, $6(5.8 \%)$ had other autoimmune diseases and $12(11.8 \%)$ had osteoarthritis. The rate of vaccination for Influenza was 49 (48\%), for pneumococcal $25(24.5 \%)$, for Herpes zoster $5(4.9 \%)$, for Human papillomavirus $9(8.8 \%)$, for Hepatitis B 14 (13.7\%) (Table 1). 82 (80.3\%) patients reported some barriers in vaccination, from these: $22(26.8 \%)$ did not get the recommendation from the rheumatologist, $21(25.6 \%)$ did not found available the vaccine, $13(15.8 \%)$ believes that vaccines don't work, $8(9.7 \%)$ had fear of adverse events, $3(3.6 \%)$ reported previous adverse events, and $15(18.2 \%)$ reported other reasons, that we classified as own decision $8(9.7 \%)$ and disinformation 7 (8.5\%) (Table 2).

Conclusion: The main barriers in vaccination of rheumatic patients reported were the lack of availability of the indicated vaccines and the medical and patient disinformation. This problem must be combated to ensure the complete vaccination of rheumatic patients.

References:

[1] Ann Rheum Dis. 2020;79:39-52.

[2] J Rheumatol. 2019;46(7):751-754

[3] Hum Vaccin Immunother. 2013;9(8):1763-73.

Disclosure of Interests: None declared

DOI: 10.1136/annrheumdis-2020-eular.5521

\section{AB1159 HIGH PREVALENCE MUSCULOSKELETAL PATHOLOGY: A CHALLENGE FOR PRIMARY ATTENDING PHYSICIANS. WHAT DO WE RHEUMATOLOGISTS CONTRIBUTE TO?}

1. García Hernández ${ }^{1}$, L. Fernández de la Fuente Bursón ${ }^{1}$, P. Muñoz Reinoso ${ }^{1}$, D. V. Mendoza Mendoza ${ }^{1}$, B. Hernández-Cruz', P. González Moreno ${ }^{1}$, J.

J. Pérez Venegas ${ }^{1} .{ }^{1}$ Hospital Universitario Virgen Macarena (HUVM), Seville, Spain

Background: Musculoskeletal Diseases (MSKD) represent one of the main health problems burdens worldwide. They cause a significant functional, quality of life and socioeconomic impact. Knee and lumbar osteoarthritis are the most prevalent ${ }^{1}$. MSKD can be assessed by different kind of specialists: Orthopedic and Traumatology Surgery (OTS), Rheumatology and Rehabilitation, each of them focused at one of the distinct aspects of the same disease. It is the General Practitioner (GP) consultations that usually act as a gateway to specialized care. However, this derivation is carried out in non-standardized manners that leads to an evaluation from a sometimes wrong selected specialist or sometimes overlap management between several of them ${ }^{2}$. The result is an endless waiting list in an overburden health system that cannot solve people's health issues. In 2018, only in our area, 32.894 patients with MSKD were referred from GP to the different medical consultations: OTS (65\%), Rehabilitation (25\%) and Rheumatology (10\%). Furthermore, there are specialized consultations called "Primary Trauma" to which GP can refer which are managed indistinctly by any of the 3 specialists mentioned before.

Objectives: The following study aims to assess by collecting data in one of these consultations, how these pathologies are referred to the different specialist and the role that the rheumatologist plays in its management.
Methods: From January to March 2019, 300 consecutive patients' medical records from the HUVM area that were sent to "Primary Trauma" consultations and attended by a rheumatologist have been reviewed. The reason for consultation, tests and referrals requested, diagnoses reached and procedures and other therapeutic actions performed were collected. Descriptive statistics with percentages and mean are showed.

Results: The average age of the patients was 51 years [7-88], 57\% (170) women and $43 \%$ (130) men. The most frequent reasons for referral were knee pain (26), foot pathology (23\%), low back pain (12\%) and carpal tunnel syndrome (6\%). 68\% (204 patients) attended the consultation with some test already performed request in primary care, mostly radiographs (61\%) and MRI scan (34\%). After the first assessment during consultation, only $31 \%$ required new studies. The diagnoses that were most frequently established are showed in table 1: degenerative knee pathology (29\%) was the most prevalent. $60 \%$ of the patients assessed were given exercise tables and/or postural recommendations. 14\% received an infiltration on the same day of the visit. Only 78 patients (26\%) needed to be reviewed later in those consultations. Of the remaining 222 (74\%), 81 (27\%) were referred to other specialists. 56 of them (19\%) went to OTS to a surgical evaluation, most frequently of the knee (32\%), hand (27\%) and foot (23\%). 141 (47\%) were discharged and referred to GP's for follow ups.

Table 1. Diagnoses.

\begin{tabular}{lcc}
\hline & N & $\%$ \\
\hline Degenerative knee pathology & 67 & 29 \\
Plantar support alterations & 34 & 15 \\
Lumbar osteoarthritis & 19 & 8 \\
Deformities of the feet & 17 & 7 \\
Mechanical metatarsalgia & 12 & 5 \\
Plantar fasciitis & 9 & 4 \\
Carpal tunnel syndrome & 9 & 4
\end{tabular}

Conclusion: The prevalence of MSKD found in medical consultation coincides with the national registers. Most patients did not need to be referred to surgical units. The role of the Rheumatologist is to take a comprehensive care for the patient, focusing on giving an effective evaluation and quick solution to his MSKD. In short, if the most prevalent MSKD are not subsidiary of surgical treatment (at least initially), the specialist whom patients with MSKD should be referred would be the rheumatologist. References:

[1] EPISER2016: Estudio de la prevalencia de las enfermedades reumáticas en población adulta en España. Sociedad Española de Reumatología. Madrid, 2018.

[2] Conill EM et al. Waiting lists in public systems: from expanding supply to timely access? Reflections on Spain's National Health System. Cien Saude Colet. 2011;16:2783-94.

Disclosure of Interests: Isabel García Hernández: None declared, Lola Fernández de la Fuente Bursón: None declared, Paloma Muñoz Reinoso: None declared, Dolores V. Mendoza Mendoza: None declared, Blanca Hernández-Cruz Speakers bureau: Abbvie, Lilly, Sanofi, BMS, STADA, Paz González Moreno: None declared, José Javier Pérez Venegas: None declared DOI: 10.1136/annrheumdis-2020-eular.4593

\section{AB1160 $\quad$ A BENCHMARKING STUDY EVALUATING THE BURDEN OF AXIAL SPONDYLOARTHRITIS IN SPAIN COMPARED WITH THE REST OF EUROPEAN COUNTRIES. RESULTS OF THE SPANISH ATLAS AND EMAS STUDIES.}

M. Garrido-Cumbrera ${ }^{1,2}$, E. Collantes-Estévez ${ }^{3,4}$, V. Navarro-Compán ${ }^{5}$, P. Zarco Montejo $^{6}$, C. Sastré ${ }^{7}$, S. Sanz-Gómez ${ }^{1}$, P. Plazuelo-Ramos ${ }^{2}$, J. GratacosMasmitja ${ }^{8,9}$ on behalf of Atlas Working Group. ${ }^{1}$ Health \& Territory Research (HTR), Universidad de Sevilla, Seville, Spain; ${ }^{2}$ Spanish Federation of Spondyloarthritis Associations (CEADE), Madrid, Spain; ${ }^{3}$ Reina Sofia University Hospital, Cordoba, Spain; ${ }^{4}$ Maimonides Biomedical Research Institute of Cordoba (IMIBIC), University of Cordoba, Cordoba, Spain; ${ }^{5}$ IdiPAZ, University Hospital La Paz, Madrid, Spain; ${ }^{6}$ Hospital Fundación Alarcón, Madrid, Spain; ${ }^{7}$ Novartis Spain, Barcelona, Spain; ${ }^{8}$ Hospital Universitari Parc Taulí, Sabadell, Spain; ${ }^{9} / 3 P T, U A B$, Barcelona, Spain

Background: Benchmarking studies in axial spondyloarthritis (axSpA) may provide evidence of disparities, making it necessary to improve the healthcare and management of these patients.

Objectives: To evaluate differences between Spain and the rest of Europe (RoE) in relation to sociodemographic characteristics, life habits, and patient-reported outcomes (PROs) in axSpA patients.

Methods: Data from 2,846 unselected patients from the European Map of Axial Spondyloarthritis (EMAS) were collected through an online survey, with 
a comparative analysis of 680 Spanish patients (2016) and 2,166 patients living in 12 other European countries (2017-2018). Socio-demographic characteristics, life habits, and PROs [BASDAI (0-10), spinal stiffness (3-12), and psychological distress (0-12, General Health Questionnaire GHQ-12)] were compared. The $X^{2}$ test was used for qualitative variables and the Mann-Whitney test applied for quantitative variables.

Results: Data from 680 (23.9\%) Spanish patients were compared to 2,166 (76.1\%) patients from the RoE. Compared to Spain, the RoE patients reported a higher percentage of females $(64.1 \%$ vs $52.5 \%$; $p<0.001)$, university studies $(51.7 \%$ vs $36.9 \% ; p<0.001)$ and higher income per family member $(€ 1,173.5$ vs $€ 823.2 ; p<0.001)$. In Spain, the proportion of respondents who were members of patient associations was higher than in RoE (44.3\% vs $37.2 \%$; $p<0.001$ ) (Table 1). Also compared to RoE, Spanish patients showed a greater diagnostic delay ( $8.5 \pm 7.7$ vs $7.2 \pm 8.6 ; p<0.001)$, HLA-B27 carriership $(77.1 \%$ vs $70.1 \% ; p=0.003$ ), and disease activity $(5.7 \pm 2.0$ vs $5.4 \pm 2.0 ; p=0.024)$. Despite lower diagnosis of anxiety and depression rates, Spanish patients reported greater psychological distress $(5.7 \pm 4.5$ vs $4.8 \pm 4.0 ; p<0.001)$. However, RoE patients declared greater spinal stiffness compared to Spanish patients $(7.8 \pm 2.4$ vs $7.5 \pm 2.7 ; p=0.009$ ) (Table 2).

Table 1. Comparison of socio-demographic characteristics and lifestyle habits of axSpA patients in Spain and in RoE

\begin{tabular}{lccc}
\hline & $\begin{array}{c}\text { Spain }(\mathrm{n}=680) \\
\text { Mean } \pm \text { SD; } n(\%)\end{array}$ & $\begin{array}{c}\text { RoE }(\mathrm{n}=2,166) \\
\text { Mean } \pm \text { SD; } \mathrm{n}(\%)\end{array}$ & $\mathrm{p}$-value \\
\hline Age (Years) & $45.7 \pm 10.8$ & $43.4 \pm 12.6$ & $<0.001^{*}$ \\
Gender (Female) & $357(52.5)$ & $1389(64.1)$ & $<0.001^{*}$ \\
Educational level & & & \\
- No schooling & $9(1.3)$ & $23(1.1)$ & $<0.001^{*}$ \\
- Primary school & $119(17.5)$ & $144(6.6)$ & \\
- High school & $301(44.3)$ & $880(40.6)$ & \\
- University & $251(36.9)$ & $1,119(51.7)$ & \\
Monthly income (€) per household member & $823.2 \pm 656.4$ & $1,173.5 \pm 928.8$ & $<0.001^{*}$ \\
Smoking & $417(71.3)$ & $1,679(77.5)$ & $<0.001^{*}$ \\
- Non-smoker or socially & $24(4.1)$ & $111(5.1)$ & \\
- Less than 10 cig/day & $144(24.6)$ & $376(17.4)$ & \\
- More than 10 cig/day & $503(86.0)$ & $1,723(79.5)$ & $<0.001^{*}$ \\
Alcohol & $37(6.3)$ & $292(13.5)$ & \\
- Never or occasionally & $45(7.7)$ & $151(7.0)$ & \multirow{2}{*}{ * } \\
- 1-2 times per week & $301(44.3)$ & $806(37.2)$ & $0.001^{*}$ \\
- More than 2 per week & & & \\
Member of a patient support group & &
\end{tabular}

Table 2. Comparison of PROs of axSpA patients between Spain and RoE

\begin{tabular}{lccc}
\hline & $\begin{array}{c}\text { Spain }(\mathrm{n}=680) \\
\text { Mean } \pm \text { SD; } n(\%)\end{array}$ & $\begin{array}{c}\text { RoE }(\mathrm{n}=2166) \\
\text { Mean } \pm \text { SD; } \mathrm{n}(\%)\end{array}$ & p value \\
\hline Diagnostic delay, years & $8.5 \pm 7.7$ & $7.2 \pm 8.6$ & $<0.001^{*}$ \\
HLA-B27 (positive) & $391(77.1)$ & $892(70.1)$ & $0.003^{*}$ \\
BASDAl (0-10) & $5.7 \pm 2.0$ & $5.4 \pm 2.0$ & $0.024^{*}$ \\
Spinal Stiffness (3-12) & $7.5 \pm 2.7$ & $7.8 \pm 2.4$ & $0.009^{*}$ \\
GHQ-12 (0-12) & $5.7 \pm 4.5$ & $4.8 \pm 4.0$ & $<0.001^{*}$ \\
Anxiety & $135(19.9)$ & $674(33.1)$ & $<0.001^{*}$ \\
Depression & $100(14.7)$ & $610(30.0)$ & $<0.001^{*}$ \\
\hline
\end{tabular}

Conclusion: In this study, significant differences between Spanish and RoE patients were observed for the burden of the disease in patients with axSpA. Patients in Spain experience a greater diagnostic delay and greater psychological distress.

Acknowledgments: Funded by Novartis Farmacéutica S.A.

Disclosure of Interests: Marco Garrido-Cumbrera: None declared, Eduardo Collantes-Estévez Grant/research support from: ROCHE and Pfizer., Speakers bureau: ROCHE, Lilly, Bristol and Celgene., Victoria Navarro-Compán Consultant of: Abbvie, Lilly, Novartis, Pfizer, UCB, Speakers bureau: AbbVie, MSD, Lilly, Novartis, Pfizer, UCB, Pedro Zarco Montejo Grant/research support from: Pfizzer, MSD, ABBVIE, Janssen, Amgen, BMS, Novartis, Lilly, Speakers bureau: Pfizzer, MSD, ABBVIE, Janssen, Amgen, BMS, Novartis, Lilly, Carlos Sastré Employee of: YES; I'm Medical Advisor in Novartis Spain, Sergio Sanz-Gómez: None declared, Pedro Plazuelo-Ramos: None declared, Jordi Gratacos-Masmitja Grant/research support from: a grant from Pfizzer to study implementation of multidisciplinary units to manage PSA in SPAIN, Consultant of: Pfizzer, MSD, ABBVIE, Janssen, Amgen, BMS, Novartis, Lilly, Speakers bureau: Pfizzer, MSD, ABBVIE, Janssen, Amgen, BMS, Novartis, Lilly

DOI: 10.1136/annrheumdis-2020-eular.5858

\section{AB1161 ARTIFICIAL INTELLIGENCE FOR RHEUMATOLOGY}

A. C. Genç ${ }^{1}$, F. Turkoglu Genc ${ }^{1}$, A. B. Kara ${ }^{2}$, L. Genc Kaya ${ }^{3}$, Z. Ozturk ${ }^{4}$,

D. Karatas ${ }^{4}$, Y. Gunduz ${ }^{2}$, E. Gönüllü ${ }^{4}{ }^{1}$ Sakarya University, Internal Medicine, Sakarya, Turkey; ${ }^{2}$ Sakarya University, Radiology, Sakarya, Turkey; ${ }^{3}$ Data Scientest, Santa Clara, United States of America; ${ }^{4}$ Sakarya University, Internal Medicine Rheumatology, Sakarya, Turkey

Background: Magnetic resonance imaging (MRI) of sacroiliac (SI) joints is used to detect early sacroiliitis(1). There can be an interobserver disagreement in MRI findings of $\mathrm{SI}$ joints of spondyloarthropathy patients between a rheumatologist, a local radiologist, and an expert radiologist(2). Artificial Intelligence and deep learning methods to detect abnormalities have become popular in radiology and other medical fields in recent years(3). Search for "artificial intelligence" and "radiology" in Pubmed for the last five years returned around 1500 clinical studies yet no results were retrieved for "artificial intelligence" and "rheumatology".

Objectives: Artificial Intelligence (AI) can help to detect the pathological area like sacroiliitis or not and also allows us to characterize it as quantitatively rather than qualitatively in the SI-MRI.

Methods: Between the years of 2015 and 2019, 8100 sacroiliac MRIs were taken at our center. The MRIs of 1150 patients who were reported as active or chronic sacroiliitis from these sacroiliac MRIs or whose MRIs were considered by the primary physician in favor of sacroiliitis was included in the study. $1441 \mathrm{MRI}$ coronal STIR sequence of 1150 patients were tagged as "active sacroiliitis" and trained to detect and localize active sacroiliitis and provide prediction performance. This model is available for various operating systems. (Image1)

Results: Precision score, the percentage of sacroiliac images of the trained model, is $87.1 \%$. Recall, the percentage of the total sacroiliac MRIs correctly classified by the model, is $82.1 \%$ and the mean average precision (mAP) of the model is $89 \%$. Conclusion: There are gray areas in medicine like sacroiliitis. Inter-observer variability can be reduced by $\mathrm{Al}$ and deep learning methods. The efficiency and reliability of health services can be increased in this way.

References:

[1] Jans L, Egund N, Eshed I, Sudoł-Szopińska I, Jurik AG. Sacroiliitis in Axial Spondyloarthritis: Assessing Morphology and Activity. Semin Musculoskelet Radiol. 2018;22: 180-188.

[2] B. Arnbak, T. S. Jensen, C. Manniche, A. Zejden, N. Egund, and A. G. Jurik "Spondyloarthritis-related and degenerative MRI changes in the axial skeleton-an inter- and intra-observer agreement study," BMC Musculoskeletal Disorders, vol. 14, article 274, 2013.

[3] Rueda, Juan C et al. "Interobserver Agreement in Magnetic Resonance of the Sacroiliac Joints in Patients with Spondyloarthritis." International journal of rheumatology (2017).
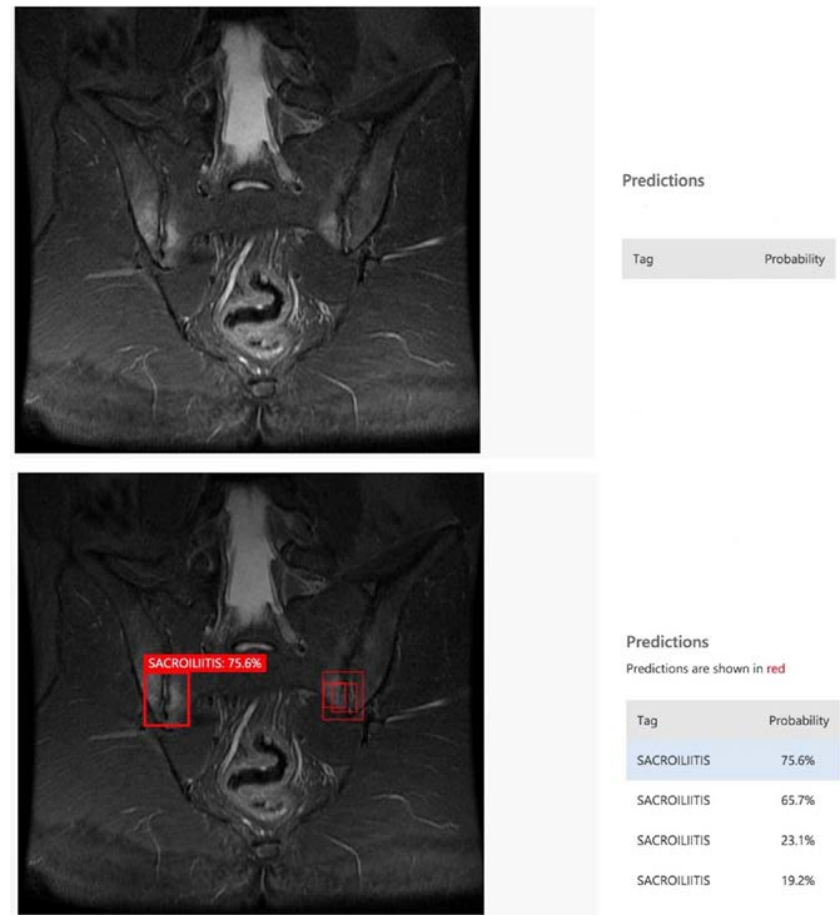

Image1. Bilateral active sacroiliitis detected automatically by AI model (in right sacroiliac joint $75.6 \%>(50 \%)$, in left sacroiliac joint $65 \%(>50 \%))$ 